\title{
KONSTRUKSI BUDAYA DAKWAH EMHA AINUN NADJIB DALAM ACARA MOCOPAT SYAFAAT SEBAGAI MEDIUM RESISTENSI
}

\author{
Nur Hanifah Insani \\ Universitas Negeri Semarang \\ Email: enhanyf@gmail.com
}

\begin{abstract}
(Title: Construction of Da'wah Culture Emha Ainun Nadjib in the "Mocopat Syfa'at" Event as a Medium of Resistance). This research studies about discourse performance of Mocopat Syafaat as a medium resistance into interesting study. This study tries to give focus to unpack and understand how texts of discourse performance and religious music are used to construct the voices of resistance and deal with changes in socio-cultural context and politics. Norman Fairclough critical discourse analysis with a qualitative approach is used to dig deeper the role of language in the construction of discourse performance of Mocopat Syafaat. This research findings suggest that the texts of the music and the contents discourse performance of Mocopat Syafaat is a powerful cultural form to ask or raise support for a movement or a case, build solidarity and social cohesion, or promote awareness.
\end{abstract}

Keywords: da'wah cultural, discourseperformance, Mocopat Syafaat, resistance

\section{PENDAHULUAN}

Dakwah dan budaya sebenarnya merupakan suatu hal yang tidak bisa dipisahkan. Keduanya saling melengkapi dan akan menjadi cacat jika dihilangkan salah satunya. Hal ini karena dalam teori unsur-unsur kebudayan, religi yang erat kaitannya dengan pengertian agama adalah salah satu unsur kebudayaan dan tidak bisa dielak lagi bahwa kebudayaan juga dapat berkembang karena adanya dakwah. Andai saja saat itu Sunan Kalijaga tidak menggunakan kesenian wayang kulit sebagai sarana penyampaian dakwah, maka belum tentu kebudayaan Jawa dapat berkembang secara pesat dan dikenal banyak orang di seantero nusantara, bahkan mendunia. Begitu juga dengan ajaran Islam tidak mungkin akan menjadi agama mayoritas penduduk Indonesia seperti sekarang ini jika dahulu dalam penyampaian dakwahnya tidak diakulturasikan dengan kebudayaan masyarakat setempat.

Model dakwah kultural seperti inilah yang kemudian juga dipakai kembali oleh Emha Ainun Nadjib atau yang sering disapa Cak Nun untuk berdakwah. Jika Sunan Kalijaga mengakulturasikan dakwahnya dengan kesenian wayang kulit, maka berbeda dengan Cak Nun yang menggunakan musik sebagai media penyampaian dakwahnya. Pengemasan musik religi dengan pencampuran perangkat gamelan dengan alat musik masa kini begitu terdengar indah di telinga. Syair-syair lagu yang dibawakan pun tak hanya sekedar lirik lagu untuk dinyanyikan, tetapi juga mengandung pesanpesan lain, entah itu pesan kebudayaan, pesan politik, sosial, dan lain-lain. Aransemen musik yang dibawakan oleh grup musik Kiai Kanjeng begitu apik dan tidak terdengar membosankan. Pada akhirnya banyak masyarakat yang menyukai cara dakwah Cak Nun tersebut. Terbukti dari banyaknya masyarakat yang berduyunduyun datang setiap kali Cak Nun beserta rombongan hadir menyampaikan dakwahnya. Dari mulai anak muda sampai kakek-nenek, semua usia menyatu dalam setiap penyampaian dakwah oleh Emha Ainun Nadjib.

EmhaAinunNadjib tidakhanya seorang pendakwah tetapi ia juga seorang budayawan yang aktif mengkritisi fenomena-fenomena sosial yang terjadi di sekitar kehidupan rakyat Indonesia. Ungkapan kritikannya banyak dituliskan dalam wujud puisi, esai, serta pementasan teater, maka tidak bisa dipungkiri jika dalam setiap dakwahnya pasti diselipkan pula kritik sosial entah bagi siapapun yang menjadi target kritikannya. Budayawan intelektual ini termasuk penganut pluralisme, dimana ideologi yang dianutnya ini pun belum tentu bisa 
diterima oleh semua orang. Dakwah kultural yang dibawakannya pun acap kali mendapat kritikan pedas, tetapi dalam anggapan Cak Nun dakwah kultural ini harus terus disebarluaskan karena masyarakat membutuhkannya sebagai upaya menggali nilai kebudayaan bangsa yang berguna untuk penyaring derasnya arus industrialisasi. Ia mengatakan, kekayaan dan keragaman kebudayaan Indonesia harus terus menerus dilestarikan dan dikembangkan oleh berbagai kalangan masyarakat. Masyarakat harus bangga dengan budaya bangsa, jangan lupakan kebudayaan. Kalau masyarakat tidak mengurusi kebudayaan, akan diisi oleh gencarnya industri. (http://www.kapanlagi.com/ showbiz/selebriti/emha-ainun-nadjib-dakwahkultural-itu-penting.html).

Kekritisan Emha Ainun Nadjib terhadap beraneka macam permasalahan bangsa Indonesia ini mulai dari masalah sosial, politik, budaya, pendidikan, dan lain sebagainya inilah yang kemudian membuat peneliti ingin mengkaji lebih dalam sebenarnya ideologi-ideologi kebudayaan seperti apa yang ingin disebarkan oleh beliau dalam penyampaian dakwah kulturalnya. Mungkin akan terlihat biasa saja jika penggalian informasi mengenai ideologi yang dibawakan oleh Cak Nun ditilik dari tulisantulisannya yang berupa puisi dan esai, tetapi dalam pengkajian kali ini yang dirasa menarik untuk dikaji jika ideologi yang dibawakan Cak Nun itu ditilik dari simbol-simbol kebudayaanya. Faktanya adalah bahwa tidak semua penceramah mampu memadukan unsur-unsur kebudayaan dengan ajaran agama khususnya ajaran agama Islam dan mampu membedah makna yang terkandung di dalamnya kemudian menanamkan ideologi tersebut kepada para pendengarnya, dan inilah yang dapat dilakukan oleh sosok Emha Ainun Nadjib.

Dari uraian di atas tampak cukup menarik untuk memposisikan dakwah kultural yang dibawakan oleh Emha Ainun Nadjib dalam konteks perubahan sosial dan politik di Indonesia. Oleh karena itu, peneliti tertarik untuk membuat kajian budaya dari wacana pertunjukan dan lagu-lagu yang disajikan oleh Emha Ainun Najib dan dibawakan bersama dengan grup musik Kiai Kanjeng. Permasalahan yang ingin dibahas dalam kajian kali ini dibatasi hanya pada ideologi apa saja serta tema-tema resistensi apa yang terdapat dalam dakwah kultural Emha Ainun Nadjib dan kepada siapa sasaran tema itu ditujukan.

Ditinjau dari segi bahasa "Da'wah" berarti panggilan, seruan atau ajakan. Bentuk perkataan tersebut dalam bahasa Arab disebut mashdar. Sedangkan bentuk kata kerja $\left(f{ }^{\prime} i l\right)$ nya berarti memanggil, menyeru atau mengajak (Da'a, Yad'u, Da'watan). Dalam pengertian istilah, dakwah menurut Prof Dr. Hamka berarti seruan panggilan untuk menganut suatu pendirian yang ada dasarnya berkonotasi positif dengan substansi terletak pada aktivitas yang memerintahkan amar ma'ruf nahi munkar. Selaras dengan Hamka, Syakih Muhammad Abduh mengatakan bahwa dakwah adalah menyeru kepada kebaikan dan mencegah dari kemungkaran adalah fardhu yang diwajibkan kepada setiap Muslim. Dari beberapa definisi di atas dapat disimpulkan bahwa dakwah juga dapat dipahami dengan proses internalisasi, transformasi, transmisi, dan difusi ajaran Islam dalam kehidupan masyarakat. (Saputra, 2012:1-3)

Dakwah memiliki tujuan yang berbeda-beda, disesuaikan dengan keinginan si pendakwah sendiri. Beberapa pola dakwah yang ada saat ini diantaranya adalah dakwah kultural, dakwah politik, dan dakwah ekonomi (ibid, hlm. 3). Berdasarkan model dakwah tersebut, maka model dakwah ala Emha Ainun Nadjib dapat digolongkang dalam dakwah kultural. Dakwah kultural adalah aktivitas dakwah yang menekankan pendekatan Islam kultural, yaitu salah satu pendekatan yang berusaha meninjau kembali kaitan doktrinal yang formal antara Islam dan negara. Dakwah kultural merupakan dakwah yang mendekati objek dakwah (mad'u) dengan memperhatikan aspek sosial budaya yang berlaku pada masyarakat. Dakwah kultural semacam ini pernah dilakukan oleh para Wali Songo dalam menyebarkan ajaran Islam di Pulau Jawa. Mereka mendakwahkan Islam kepada masyarakat Jawa dengan sangat memperhatikan tradisi dan adat istiadat yang berlaku di masyarakt Jawa pada saat itu. Hasilnya cukup efektif terbukti dengan banyaknya masyarakat Jawa yang tertarik dengan ajaran Islam. (ibid, hlm. 3) 
Media dakwah adalah segala sesuatu yang dapat dipergunakan sebagai alat untuk mancapai tujuan dakwah yang telah ditentukan. Media dakwah ini dapat berupa barang (material), orang, tempat, kondisi tertentu dan sebagainya (Syukir, 1983: 163). Musik merupakan salah satu jenis kesenian yang menggunakan nada dan irama sebagai sarananya, dimana kesenian sendiri merupakan salah satu unsur kebudayaan. Seni atau kesenian menurut Anshari (1986:116) adalah manifestasi budaya (priksa, rasa, karsa, intuisi, dan karya) manusia yang memenuhi syarat-syarat estetik. Keindahan seni merupakan suatu hal yang menyenangkan. Hal ini senada dengan definisi seni menurut Herbert Read dalam Sidi Gazalba (1989:299), seni adalah usaha untuk menciptakan bentuk-bentuk yang menyenangkan. Sedangkan definisi musik dalam Kamus Besar Bahasa Indonesia adalah nada atau suara yang disusun sedemikian rupa sehingga mengandung irama, lagu, dan keharmonisan (terutama yang menggunakan alat-alat yang dapat menghasilkan bunyi-bunyi) (Depdiknas, 2002: 766). Pengertian ini juga tidak berbeda dengan WJS Poerwadarminta (1976: 614) yang mendefinisikan musik sebagai bunyi-bunyian.

Musik dan dakwah merupakan naluri manusia sejak lahir yang diberikan Allah SWT. Sudah menjadi kesepakatan para ahli bahwa musik memiliki arti penting dari sudut pandang spiritual, tidak hanya bagi musik itu sendiri, melainkan juga dalam hubungannya dengan syair, sebagaimana ditunjukkan dengan amat menarik oleh Maulana Jalaluddin Rumi. Kalau melihat sejarah, sesungguhnya upayaupaya menyampaikan ajaran Islam melalui media seni sudah memiliki umur yang relatif tua. Sunan Kalijaga dan Sunan Bonang, misalnya adalah dua dari sekian banyak tokoh penyebar Islam yang menjadikan musik sebagai media dakwah. "Sunan Kalijaga abad ke-21," yakni Emha Ainun Nadjib, juga melakukan hal yang sama melalui musikalisasi kelompok musik Kiai Kanjengnya. la sanggup mengubah gamelan yang berasal dari tradisi Jawa tersebut menjadi sarana pengungkapan dan penyampaian pesan-pesan dakwah kepada masyarakat. Musik Kiai Kanjeng dan puisi Emha Ainun Nadjib tidak memfokuskan perhatiannya ke- pada musik dan puisi itu sendiri. Hal ini karena musik dan puisi bukan pusat kehidupan manusia melainkan fasilitas estetika dalam kebudayaan masyarakat. Musik dan puisi mempermudah komunikasi, memperindah pergaulan, memperdalam cinta. mempercepat keharuan keilahian.

Berkaitan dengan relasi antara Islam sebagai agama dengan budaya lokal sangat jelas kaitannya dan hal ini dapat ditinjau dalam kajian antropologi agama. Dalam perspektif ini diyakini bahwa agama merupakan penjelmaan dari sistem budaya. Islam sebagai agama samawi dianggap merupakan penjelmaan dari sistem budaya suatu masyarakat Muslim (Tibbi dalam Zuhdi, 2012:52).

Islam sebagai agama, kebudayaan dan peradaban besar dunia mengalami perkembangan secara signifikan sampai saat ini di seluruh pelosok muka bumi termasuk Indonesia. Munculnya agama Islam di tengah-tengah kebudayaan masyarakat Indonesia zaman dahulu yang telah terlebih dahulu menganut kepercayaan animisme dan dinamisme telah memunculkan beraneka jenis kebudayaan nusantara yang baru. Akulturasi budaya yang berkembang dalam kehidupan masyarakat Indonesia zaman dahulu dengan tradisi Islam yang agung telah memperkaya pluralitas tradisi-tradisi baru di tengah-tengah masyarakat. Islam telah memperkaya pluralitas dengan islamisasi kebudayaan dan pribumisasi Islam yang pada gilirannya banyak melahirkan tradisi-tradisi keci Islam. Bukti otentiknya yaitu dengan munculnya berbagai macam warna Islam di nusantara ini mulai dari Islam gaya Aceh, Jawa, Sunda, Sasak, dan lain sebagainya (ibid, hlm. 52).

Kajian budaya (culturalstudies) merupakan suatu wacana yang luas untuk merespon kondisi politik dan historis yang senantiasa berubah dan selalu ditandai dengan perdebatan, ketidaksetujuan, serta intervensi. Budaya dalam hal ini lebih didefinisikan secara politis daripada secara estetis. Objek kajian dalam cultural studies disini bukanlah pengertian budaya secara sempit tetapi lebih luas dimana budaya dipahami sebagai teks dan praktik kehidupan sehari-hari. Studi budaya ini juga dilihat sebagai situs penting bagi produksi dan reproduksi 
hubungan sosial dalam kehidupan sehari-hari. Stuart Hall dalam Storey (1994:278) menjelaskan bahwa:

Cultural Studies mengandungi wacana yang berlipat ganda; bidang ini memuat sejumlah sejarah yang berbeda. Cultural Studies merupakan seperangkat formasi; ia merekam momenmomen di masa lalu dan kondisi krisisnya (conjuncture) sendiri yang berbeda. Cultural Studies mencakupi pelbagai jenis karya yang berbeda... ia senantiasa merupakan seperangkat formasi yang stabil...ia mempunyai banyak lintasan; kebanyakan orang telah mengambil posisi teoritis yang berbeda, kesemuanya teguh pada pendiriannya.

Penelitian ini ingin menempatkan kajian dakwah yang diiringi musik sebagai media dakwahnya dalam konteks kajian budaya dan komunikasi politik dengan melihat kaitan dan akarnya dengan studi-studi terdahulu.

Konsep resistensi budaya telah menarik perhatian banyak orang terutama para pengkaji budaya. Pandangan bahwa resistensi selalu hidup dalam kehidupan sehari-hari masyarakat kapitalis semakin membuat konsep resistensi sebagai tema yang menarik untuk dikaji. Menurut Slemon (dalam Lahpan, 2002:20) resistensi dijelaskan sebagai tindakan atau sekumpulan tindakan yang dibentuk untuk membebaskan rakyat dari penindasnya, dan memasukkan secara keseluruhan pengalaman hidup di bawah penindasan yang menjadi prinsip estetika yang hampir otonom. Para ilmuwan yang mengkonseptualisasikan resistensi dari sudut pesan dan proses komunikasi mencoba untuk meng-counter struktur kekuasaan dominan (yakni, upaya-upaya untuk memelihara status quo); mereka memperlakukan resistensi sebagai sesuatu yang aktif dan manifestasi dalam bentuk praktik komunikatif (Cheney \& Cloud, 2006). Upaya menteorikan resistensi membuka kemungkinan untuk mengkonseptualisasikan dan melakukan perubahan sosial dalam arena global, menantang struktur kekuasaan dominan yang menciptakan dan memelihara kondisi marjinalisasi, dan me- nampilkan suara-suara sektor-sektor budaya dan ekonomi yang termarjinalkan dalam dunia global yang kompleks dimana secara historis telah dibisukan oleh aktor-aktor yang kuat.

Stuart Hall dalam Deconstructing the Popular mendiskusikan konsep resistansi secara lebih rinci:

The cultural industries do have the power constantly to rework and reshape what they represent, and by repetition and selection, to impose and implant such definitions of ourselves as a fit more easily the descriptions of the dominant or preferred culture. That is what the concentration of cultural power - the means of culture making in the heads of the few - actually means. In our times, it goes on continuously, in the complex lines of resistance and acceptance, refusal and capitulation, which make the field of culture a sort of constant battlefield (Hall, 1981: 187).

\section{METODE}

Kajian ini menggunakan paradigma kritis. Dalam tulisan (Hidayat, 1999) paradigma kritis tujuannya melakukan kritik sosial, transformasi hubungan sosial yang timpang, emansipasi dan penguatan sosial. Realitas yang dilihat dan diangkat adalah historical realism, yaitu realitas semu yang terbentuk dalam proses sejarah dan kekuatan sosial, budaya dan ekonomi politik. Paradigma kritis mencoba menggambarkan bahawa kondisi kapitalisme begitu berperanan besar terhadap segala bidang. Kondisi ini bagi aliran kritis sangat tidak disadari oleh masyarakat. Ia tidak sekadar mengamati tetapi juga melakukan kritik. Tujuan teori kritis menyadarkan masyarakat tentang segala hal dan bersipat emansipatoris. Studi kritis memfokuskan perhatiannya pada issue-issue ketidaksamaan (inquality) dan penindasan (oppresiaon). Bicara tentang konflik kepentingannya dalam masyarakat dan cara komunikasi mengekalkan dominasi suatu kelompok ke kelompok yang lain. (Little John, 1999)

Teknik analisis data yang digunakan adalah analisis wacana kritis. Analisis wacana kritis (critical discourse analysis) tidaklah menyiratkan suatu metode yang homogen dalam 
analisis wacana (Titscher, dkk, 2009:235). Analisis wacana kritis menyediakan teori dan metode yang bisa digunakan untuk melakukan kajian empiris tentang hubungan-hubungan antara wacana dan perkembangan sosial yang berbeda (Jorgensen \& Phillips, 2007:114). Ada beberapa pendekatan-pendekatan yang berbeda dalam pengkajian analisis wacana kritis, tetapi pada prinsipnya ada lima ciri-ciri umum analisis wacana kritis yang dikemukakan oleh Norman Fairclough dan Roth Wodak, yaitu (1) sifat struktur dan proses kultural dan sosial merupakan sebagian linguistik-kewacanaan; (2) wacana itu tersusun dan bersifat konstitutif; (3) penggunaan bahasa hendaknya dianalisis secara empiris dalam konteks sosialnya; (4) fungsi wacana secara ideologis; dan (5) penelitian kritis (Jorgensen \& Phillips, 2007:115121).

Ada beberapa model analisis wacana kritis yang dikemukakan oleh para ahli, tetapi pada kajian ini model analisis wacana kritis yang dipakai milik Norman Fairclough. Hal ini karena dalam melakukan analisis wacana kritis ini Fairclough (1992a) telah membuat sketsa suatu kerangka kerja tiga dimensi untuk memahami dan menganalisa wacana. Dimensi pertama adalah wacana-sebagai-teks, yakni karakteristik bahasa dan organisasi instansi kongkret wacana. Dimensi kedua adalah wacana-sebagai-praktik-diskursif, yakni wacana sebagai sesuatu yang diproduksi, diedarkan, disebarkan, dan dikonsumsi di dalam masyarakat. Dimensi ketiga adalah wacanasebagai-praktik-sosial, yakni efek ideologi dan proses hegemonik yang di dalamnya wacana adalah suatu feature. Ideologi, bagi Fairclough, merupakan "makna yang melayani kekuasaan" (Fairclough, 1995b: 14). Lebih tepatnya, ia memahami ideologi sebagai pengonstruksian makna yang memberikan kontribusi bagi pemroduksian, pereproduksian dan transformasi hubungan-hubungan dominasi (Fairclough, 1992b: 87). Ideologi tercipta dalam masyarakat-masyarakat. Di sinilah hubungan dominasi didasarkan pada struktur sosial seperti kelas dan gender. Hegemoni menaruh perhatian pada kuasa yang dicapai melalui pembentukan aliansi dan pengintegrasian kelas dan kelompok melalui kesepakatan, sehingga “artikulasi dan reartikulasi tatanan wacana merupakan hal yang dipertaruhkan dalam perjuangan hegemonik" (Fairclough 1992a: 193). Menurut definisi Fairclough, wacana bisa kurang lebih bersifat ideologis, wacana ideologis yang memberikan kontribusi bagi usaha untuk mempertahankan dan mentransformasikan hubungan-hubungan kekuasaan.

\section{HASIL DAN PEMBAHASAN Hasil}

Penelitian ini menggali jalur resistensi dan memandang ruang musikal sebagai lahan pertempuran budaya. Untuk tujuan penelitian ini, adalah penting untuk mempertegas bagaimana resistensi didefinisikan dan dikarakteristikkan. Hollander dan Einwohner (2004), mengusulkan agar lebih banyak perhatian harus dicurahkan pada definisi resistensi, dan bagaimana ia secara sosial ditempatkan pada tingkatan individu, kolektif, dan institusional dari kehidupan manusia. Berbagai definisi resistensi diajukan seperti, "acting autonomously in one's own interests; active efforts to oppose, fight, and refuse to cooperate with or submit to abusive behavior and control"; and simply "questioning and objecting" (Hollander dan Einwohner, 2004: 538). Bahwa resistensi selalu berhubungan dengan gagasan kekuasaan, ketidakadilan, dan perubahan sosial. Resistensi ini bisa dilakukan melalui pembicaraan dan perilaku simbolik lainnya, ia bisa bersifat individual atau kolektif, tersebar atau ditentukan secara lokal, dan ia dapat berlangsung dengan sedikit atau tidak ada koordinasi di antara pelaku atau subjek (Hollander dan Einwohner, 2004: 538).

Resistensi budaya dengan demikian mengandaikan kesadaran individu dan kemampuan individu untuk mengartikulasikan maknamakna alternatif terhadap makna sebagai hasil dari konstruksi kelompok dominan. Resistensi seperti ini juga menekankan pada kekuatan wacana dan simbol. Mengingat kekuatan wacana dan simbol untuk mengorganisasikan dan mengaktifkan identitas kolektif, misalnya, juga bisa berlangsung melalui jalan perubahan performatif seperti lewat teater jalanan, teater protes, lagu-lagu perlawanan, dan tarian per- 
lawanan (Boal, 1985, 1998; Chatterjea, 2004; Hashmi, 2007).

Analisis teks memfokuskan pada fungsi level mikro dan proses-proses konstruksi realitas sosial dalam dan melalui teks. Balliger (1999) mencatat bahwa di dalam bidang kajian musik populer, gagasan "politik" segera menunjuk langsung pada lagu-lagu protes atau musik protes. Di dalam dunia musik pop juga, tampak bahwa ketika politik dan musik secara eksplisit berbaur, maka seorang pendengar yang mendengar setiap lagu bekerja sebagai "perjuangan melawan institusi dominan seperti negara dan sistem ekonomi" (Balliger, 1999:57). Kita bisa mengatakan bahwa musik (populer dan sebaliknya) memiliki struktur politik dan $\mathrm{ka}$ pasitas pembentuk-polity (masyarakat politik) di dalam dirinya (Kotarba dan Vannini, 2009). Karena itu di dalam musik sesungguhnya terkandung kekuatan yang hanya bisa diungkapkan oleh kekuatan ungkapan teks-teks musik itu sendiri.

\section{Pembahasan}

Dalam analisis wacana kritis, analisis ungkapan adalah salah satu sarana untuk melakukan analisis produksi teks dalam praktik kewacanaan. Analisis ini akan dilakukan untuk menjelaskan dan mengidentifikasi kekuatan ungkapan atau kekuatan pengucapan dalam album ini. Menurut Fairclough (2013), kekuatan ungkapan adalah fungsi wicara seperti pernyataan, tuntutan, tawaran/usulan, pertanyaan, atau pengakuan yang dimanipulasi dalam produksi wacana. Kekuatan ungkapan bisa diperinci misalnya ke dalam beberapa tindak wicara seperti janji, ancaman, permintaan, pembelaan, apologi. Tindak wicara bisa bersifat menyanjung, mendeklarasikan, mengarahkan, ekspresif, dan representatif.

Dalam hal ini analisis kekuatan ungkapan ini bisa dilihat dari kekuatan wacana musik yang disajikan oleh Emha Ainun Nadjib beserta grup musik Kiai Kanjengnya dalam setiap acara ceramahnya. Teks-teks lagu yang sering dibawakan beserta isi-isi ceramahnya seringkali mengarahkan tindak wicara untuk melawan atau menyuarakan suara perlawanan terhadap persoalan atau isu tertentu yang berlangsung dalam masyarakat. Dari analisis kekuatan ungkapan terhadap lagu-lagu Kiai Kanjeng beserta petikan isi ceramah Cak Nun ini ditemukan beberapa tema dan suara perlawanan yang selama ini menjadi ciri ideologi perlawanan yang selalu muncul melalui musik seperti yang berlaku di berbagai kawasan di dunia yang lain. Kajian ini bisa menjelaskan praktik sosial yang tersembunyi di balik suatu wacana.

Analisis wacana terhadap lirik-lirik lagu yang sering dibawakan oleh Kiai Kanjeng baik yang ditulis sendiri oleh Cak Nun maupun yang telah diaransemen menunjukkan bahwa dalam teks-teks musiknya hidup pergulatan wacana dan batin si musisi yang mencerminkan keinginan mereka dalam membangun otonomi musisi dan musik otonom. Tipe musik seperti ini, mengikuti uraian Kotarba dan Vannini (2009), termasuk dalam kategori-kategori seperti lagu atau musik yang menawarkan suara alternative berupa: (1) Protes terhadap Opresi dan Eksploitasi; (2) Satire terhadap Kekuasaan; (3) Inspirasi bagi Gerakan Kolektif; (4) Penghormatan terhadap Pahlawan atau Martir; dan (5) Komentar Sosial Kritis.

Politik memasuki musik, dan musik memasuki politik, dalam berbagai cara dan seringkali halus. Kajian terhadap musik populer mungkin akan menemukan nilai-nilai politis pada lagu-lagu yang tidak ada satu kata pun ajakan untuk melakukan tindakan protes atau patriotisme. Apalagi kalau kita melihat pandangan seperti Theodor Adorno (Adorno dan Hullot-Kentor, 2006), bahwa proses membuat seperti kekanak-kanakan atau "infantilisasi" lagu-lagu pop (the infantilization of pop songs) seperti itu sekaligus merupakan simptom dan sebab formasi sebuah budaya massa.

\section{Satire terhadap Kekuasaan}

Lagu merupakan salah satu media yang dapat digunakan untuk menyampaikan gagasan, kritik, maupun sindiran terhadap suatu hal. Lirik lagu Demak Ijo yang sering dinyanyikan oleh grup musik Kiai Kanjeng dalam setiap pementasannya juga menganut sindiran terhadap pemerintah Indonesia pada saat diciptakannya lagu ini. Berikut merupakan lirik lagu Demak Ijo: 


\author{
Demak Ijo \\ Yo padha dolan neng demak ijo, ayo jo \\ Jothakan ku, ayo ku \\ Kusir jaran, ayo ran \\ Rante kapal, ayo pal \\ Palu arit, PKI, ayo I \\ Iwak Babi, ayo bi \\ Bintang sabit, Masyumi, ayo mi \\ Minak jinggo, ayo nggo \\ Nggodhog tela, ayo lo \\ Londo mendem, ayo ndem, \\ Ndemok silit, gudhigen...
}

Lirik lagu di atas merupakan suatu sindiran terhadap pemerintahan Orde Lama dimana dalam kekuasaannya banyak terdapat gerakan komunis PKI yang meresahkan masyarakat. Pada masa Orde Lama juga banyak berkembang gerakan-gerakan lain sebagai tandingan seperti Masyumi yang merupakan gerakan ormas Islam. Kata "Minak Jinggo" disini merupakan simbol penguasa yang sedang berkuasa pada saat itu. Penguasa pada masa Orde Lama masih dibayang-bayangi oleh pengaruh negara asing yang pada saat itu berimplementasi dalam wujud PKI. Akhirnya semua hal dalam pemerintahannya mendapat ikut campur dari pihak asing. Pengemasan sindiran terhadap pemerintah ini dikemas dalam wujud ungkapan yang berbau erotis. Begitu pula lirik lagu yang terdapat dalam lagu Esuk-esuk dimana pengemasannya masih berbau erotis, tetapi tetap saja pada akhirnya hal yang dituju adalah sindiran akan banyaknya pejabat pemerintahan yang terlibat kasus korupsi.

Sindiran terhadap kekuasaan yang semakin menjadi-jadi juga disampaikan oleh Emha Ainun Nadjib dan Kiai Kanjeng dalam lirik lagu Rampak Osing berikut ini.

\section{Rampak Osing}

Arep golek apa $2 x$ kok uber - uberan

Padha ngoyak apa $2 x$ kok jegal-jegalan

Kabeh dha mendem $2 x$ rak mari - mari

Bandha kuwasa rak digawa mati

Rina wengi aku tansah ngenteni...,

suara kang sejati

Kina lan warsa gilir gumanti...,

tumeka titi wanci

Dhuh Gusti kang murbeng dumadi
Pandika kang ngasta wewanti.

Kawula nyuwun pandhawuhe......

Lirik lagu Rampak Osing ini menggambarkan kondisi bangsa saat ini yang carutmarut dan semakin tidak karuan lagi orangorangnya. Sesama pejabat saling mencari kesalahan pejabat lainnya hanya demi berebut tahta dan kekuasaan. Harta benda dicari semua orang dengan cara yang berbeda-beda. Kemerlapnya harta ternyata telah membutakan mata banyak orang dalam mencari nafkah untuk keluarganya. Sekarang harta tidak hanya dicari untuk sekedar mencukupi kebutuhan keluarganya, tetapi sudah untuk keperluan pamer harta. Ketika harta sudah membutakan mata, maka sekarang hanya suara Tuhan sajalah yang dapat membuka hati nurani setiap orang agar sadar akan niatnya yang belum benar.

Kalau dilihat dari kasus yang sedang berkembang hangat saat ini di tengah masyarakat yakni tentang kasus POLRI versus KPK. Kedua lembaga pemerintahan tersebut bukannya saling bantu membantu mencari kebenaran dan keadilan, tetapi saling menjatuhkan satu sama lain. Entah siapa yang benar maupun siapa yang salah. Yang jelas sebenarnya yang salah bukan lembaganya tetapi oknum-oknum yang terlibat kasus di dalamnya yang kemudian mencari pembelaan diri hanya untuk menutupi kesalahan dirnya sendiri dengan membuat orang lain sebagai tumbalnya.

Penyampaian sindiran terhadap pemerintah juga tercantum dalam lirik lagu Hanacaraka yang ditulis oleh Emha Ainun Nadjib. Bahasa yang digunakan dalam penulisan lagu ini lebih kasar lagi. Mungkin ini sebagai sebuah ungkapan kejengkelan dan kekecewaan yang mendalam terhadap jalannya pemerintahan bangsa Indonesia ini. Semua pejabat negara maupun pemerintahan sekajan tak punya rasa malu lagi akan semua tingkah laku yang telah mereka kerjakan. Para oknum yang senantiasa memanfaatkan keadaan itu tidak lebihnya seperti anjing. Orang-orang bodoh yang sekarang sedang nyaman dengan jabatannya itu tidak diharapkan hidup lebih lama lagi karena mereka hanya akan lebih menyengsarakan rakyat jika bertengger di posisinya lebih lama. Jiwa seniman nya telah keluar dengan ungkapan kata- 
katanya yang frontal. Berikut ini merupakan lirik lagu Hanacaraka yang ditulis oleh Cak Nun.

\section{Hanacaraka}

Kae ketoke kaya babi, jebul tak sawangsawang babi tenan

Hanacaraka Datasawala, padha pekok o mangga modar o

Lha nek sing ning kana kae kirik apa asu, jebule nek ora asu yo kirik

Hanacaraka Datasawala, padha pekok o mangga modar o

Waji'an waji'an kae pancen, waji'an kae pancen waji'an

Gusti Allah ngentukke kowe misuh ap ora, nek pancen atimu lara banget suwe banget misuh kuwi wajib hukume

Hanacaraka Datasawala, padha pekok o mangga modar o

Apa bedane rai karo silit nek rai dadekne silit, nek silit dadekne rai

Hanacaraka Datasawala, padha pekok o mangga modar o

Bajinguk bajinguk kae pancen, bajinguk cen pancen padha munyuk.

Jika kita telaah ternyata penggunaan kalimat "hanacaraka datasawala" itu ada maknanya, dan justru disinilah sindiran akan kekuasaan itu ditampakkan. Arti "hanacaraka" adalah ada utusan. Lalu siapa yang mengutus dia? Partai, rakyat, atau Tuhan kah? Lalu untuk apa/siapa dia yang diutus? Partai, rakyat, atau Tuhan? Secara umum, pengutus atau pendelegasi berasal dari lembaga yang bernama Partai, dari urusan dewan sampai urusan presiden adalah "ulah" pendelegasian Partai. Jika rakyat sudah muak dengan para calon yang diusung menjadi caraka/utusan, maka rakyat bisa mandiri dalam menentukan siapa yang layak menjadi caraka bagi mereka. Perihal tersebut tidaklah bisa terjadi begitu saja. Jika rakyat sudah memutuskan sendiri siapa carakanya, berarti wilayah itu sudah tidak lagi kondusif; class, chaos, cup dan lain sebagainya, bisa dipastikan hal tersebut tengah mewarnai situasi negeri tersebut, bahkan sebelum kehendak rakyat itu ter-blowup. Untuk wilayah yang tidak bisa ditolak adalah jika dia adalah caraka Tuhan. Jika
Tuhan sudah berkehendak, bisa melalui tragedi atau tidak sama sekali, terserah Tuhan. Hal ini urusan bukan untuk dibahas detailnya, karena sudah ada yang menanganinya.

Lalu, arti kata "datasawala" yaitu seorang pemegang janji/amanat. Utusan itu berjanji setia pada partai, karena diutus partai. Utusan itu berjanji setia pada rakyat, karena diutus rakyat. Utusan itu berjanji setia pada Tuhan, karena diutus Tuhan. Ada caraka sejati, ada yang caraka abu-abu/palsu. Hal ini sangat lumrah, karena setiap diutusnya seorang pemegang amanah selalu disertai beberapa yang palsu. Sejak zaman kenabian pun juga seperti itu, selalu ada nabi palsu disaat yang sama di zaman kenabian tersebut. Hal ini memang setting Tuhan untuk membedakan bahwa; mana yang benar dan mana yang salah, umat yang beriman dan umat yang masih ragu atau umat yang tidak beriman. Jika disudutkan pada dua/ lebihpilihan, untuk membedakan mana caraka sejati dan yang abu-abu, bagaimana membedakan/mengenalinya? Jikalau saja, manusia lebih mau bercengkrama dengan alam (walau sedikit) tanda itu pasti akan nampak. Karena ketika sebuah "keputusan langit" telah ditetapkan untuk manusia, alam tidak akan tinggal diam. Alam akan menyambut dengan caranya sendiri, "sekecil" apapun "keputusan langit", alam pasti turut merayakannya, turut mensyukurinya. Alam turut bersyukur bahwa Tuhan masih mau memperhatikan dan sayang pada manusia. Jika ada kepekaan dan kepedulian manusia pada alam, semakin peka manusia, semakin besar pula mereka memberikan tandatanda itu pada manusia.

Satire terhadap pemerintah itu tidak hanya disampaikan melalui lagu dan musik semata, akan tetapi seringkali dan pasti dalam setiap ceramahnya Emha Ainun Nadjib selalu mengaitkan dakwahnya dengan hal-hal yang berbau kekuasaan walaupun tidak mendalam pembahasannya. Salah satunya dalam petikan ceramahnya berikut ini.

“... Semua orang pengin kaya, maka jangan bicara KPK POLRI karena itu urusannya bukan urusan hukum, maka jangan berbicara tentang itu. Urusannya adalah tetep tentang memperkaya diri. Pura-pura demokrasi, pura-pura 
hukum, pura-pura pasal, pura-pura peradilan."

Dalam ungkapannya seperti yang telah disebutkan di atas, Emha Ainun Nadjib yang juga seorang kritikus selalu mengkritisi apaapa yang telah dan sedang terjadi pada bangsa Indonesia ini. Dari kasus-kasus lama sampai kasus-kasus terhangat diketahui oleh beliau dan analisisnya akan saling terkait. Secara terang-terangan Cak Nun juga berani menyindir pihak-pihak yang ikut terlibat dalam upaya penguasaan bangsa oleh kelompok tertentu, baik itu partai politiknya maupun para politisinya. Semua diceritakan secara gamblang oleh Cak Nun tanpa ada rasa takut dalam pengungkapan setiap kasus yang terjadi. Setiap kasus yang terasa ganjil dianalisis dan dicari asal muasalnya. Hal ini mungkin saja terjadi karena Emha Ainun Nadjib sejatinya merupakan saksi sejarah dari masa Orde lama lalu menjadi bagian dari Orde Baru dan masih hidup di era Reformasi sekarang ini. Jadi, beliau memang mengetahui kejadian-kejadian yang sebenarnya terjadi di masa lalu. Pengalamannya dalam bidang politik telah menuntunnya menjadi seorang pengamat politik sekaligus kritikus yang bisa dikatakan berani pada masa sekarang ini. Namun demikian Emha Ainun Nadjib bukanlah orang yang mau secara langsung terlibat dalam urusan politik. Sekarang ini beliau hanya ingin bersama-sama dengan masyarakat membenahi sikapnya dengan berfikir lebih logis dan kritis lagi, jangan menelan secara mentah-mentah isu-isu yang sedang tren. Kemudian setelah semua penyampaian curahan hati beliau ini pasti akan diselingi motivasi-motivasi kebaikan yang ditujukan untuk semua pihak termasuk dirinya pribadi.

Lirik-lirik lagu yang menyiratkan inspirasi untuk kehidupan yang lebih baik juga tergambarkan dalam lagu "Yatim" berikut ini.

\section{Yatim}

Aduh Gusti kula niki anak yatim

Bapak pejah emak kula tiyang miskin

Lamung enjing emak kula mlaku-mlaku

Pados sandhang pangan kalih buruh nutu

Lamun siyang emak kula buruh adang

Pados sangu pangupa jiwane gesang
Lirik lagu di atas menggambarkan perjuangan seoranga ibu yang rela banting tulang mencari nafkah untuk menghidupi anakanaknya. Berbagai macam jenis pekerjaan rela ia lakukan mulai pagi sampai malam hari. Ditinggal mati suaminya tidak membuat ia lalu berputus asa mengakhiri kehidupannya. Justru setiap peluang yang ada ia masuki teriring kerja keras yang tak kenal lelah.

\section{Sejarah yang Terlupakan}

Dalam menyampaikan dakwahnya, Emha Ainun Nadjib juga kadang-kadang membukakan rahasia sejarah masa lalu yang tidak diketahui semua orang. Tentu saja apa-apa yang diceritakan itu berkaitan dengan kehidupan yang telah dialami sendiri olehnya. Kiprahnya yang pemberani membuat ia tak sungkan menjalin persahabatan dengan orang-orang besar di Indonesia. Meskipun beliau bukan seorang politikus ulung di Indonesia ini tetapi pengalamannya di bidang politik tidak bisa dipandang sebelah mata, karena ia dapat menimba ilmu langsung dari para pelaku politik yang berpengaruh pada bangsa ini di masa lalu. Berikut ini merupakan kutipan sedikit sejarah yang terlupakan oleh bangsa Indonesia yang disampaikan Cak Nun dalam beberapa dakwahnya.

“... Aku ki nak kepengin nuntut nang Indonesia, tak tugel kabeh gulune, edan nopo? Aku wis mentri biyenbiyen, wis presiden biyen-biyen no? Rumangsamu sing ngedhunke Suharto sapa? Sing ngunggahke Gus Dur sapa? Sing ngedhukke Gus Dur sapa? Akeh banget riwayat sing dimanipulasi oleh reformasi, nak tak tuntut hak ku kuwi, kadang-kadang po tak tuntut hak $k u$ kuwi ya? Tak tuntut kuwi nak diidinke. Nak ra diidinke yo ra masalah wong aku ra dadi apa-apa ya ra masalah, wong enak tenan kok uripku iki, wis ana Novia arep napa...?"

Berdasarkan apa yang disampaikan Cak Nun tersebut dapat dimengerti bahwa sebenarnya beliau merupakan salah seseorang yang menjadi saksi hiruk pikuk politik yang telah terjadi di Indonesia dari zaman orde baru 
hingga saat ini. Ungkapan yang pertama mengisyaratkan bahwa Emha Ainun Nadjib termasuk salah seorang yang juga ikut menggulingkan kekuasaan Suharto di era orde baru. Walaupun begitu setelah keikutsertaannya menghapuskan zaman pemerintahan yang bobrok penuh dengan KKN, beliau tidak mau menjabat menjadi salah satu oknum di pemerintahan. Cak Nun lebih memilih untuk pulang kampung dan mulai berdakwah sehingga nantinya ia bisa dekat dengan Gus Dur. Kedekatannya dengan Gus Dur dapat terlihat dalam ungkapan paragraf kedua di atas.

\section{Problematika Ketauhidan}

Isi dakwah yang disampaikan oleh Emha Ainun Nadjib baik yang melalui tutur katanya langsung maupun melalui lagu-lagu yang disampaikan tak semuanya berbau politik. Esensi dakwah sendiri yang senantiasa mengingat kebesaran Tuhan juga tidak luput menjadi salah satu poin terpenting dalam setiap yang ia sampaikan. Cak Nun tak pernah berhenti mengingatkan semua jamaahnya agar selalu mengingat Allah karena hidup ini tidaklah abadi. Gambaran ketidakabadian ini yang kemudian ditulis dalam lirik lagu "Sinau Mati" berikut ini.

\section{Sinau Mati}

Sinau mati sajroning urip,

Supaya suk yen mati dikersakake urip,

Sing urip sakjane mati,

Sing rumangsa mati sejatine urip

Sing wongira urip kuwi jane mati,

Sing rumangsa mati sejatine urip

Gusti Allah urip jinumuk sing na mati,

Gusti Rahmat karya mati saka sajroning urip,

Aywa na mati mung sumayawana,

Gusti kang sari ana mung titah rumangsa ana,

Anane ana ming kinarya ana,

Gusti pancene ana bocah rumangsa ana

Lirik lagu di atas menggambarkan bahwa di dalam kehidupan ini kematian itu pasti akan terjadi dan ketika semua itu terjadi yang tersisa hanyalah Tuhan saja. Allah itu ada dimanapun manusia berada dan memang benar-benar ada. Sayangnya, kondisi yang ter- jadi saat ini bahwa rasa mengingat keberadaan Tuhan ini sudah mulai hilang. Manusia membangga-banggakan manusia lain bahkan dirinya sendiri juga turut dibanggakan. Manusia tidak ingat bahwa semua keberhasilan yang mereka dapat selama hidupnya itu karena Tuhan. Manusia merasa bahwa semua keberhasilan yang mereka dapatkan adalah hasil usahanya sendiri. Mereka membutakan kehidupan ini dengan hal-hal keduniawian yang akhirnya membuat mereka tidak sadar bahwa kematianlah yang sebenarnya sedang mereka rasakan. Tetapi, tidak semua orang mendewa-dewakan gemerlapnya duniawi. Masih ada pula orang yang menyadari kebesaran dan keberadaan Tuhan di setiap langkah hidupnya. Mereka tidak berani menyatakan bahwa dirinya lebih kuasa daripada Tuhan dan mereka inilah yang sebenarnya merasakan kehidupan yang sejati. Kegelapan dalam kehidupan mereka rasakan bak kematian yang telah merenggut jiwanya, tetapi kematian yang semu inilah akar dari sinar kehidupan yang indah.

Gambaran ketidakberdayaan seorang manusia di bumi ini juga dituliskan dalam lirik lagu "Ingsun Amemuji". Dalam lagu ini dijelaskan bahwa manusia itu tempatnya dosa bersarang, maka yang dapat ia lakukan hanyalah memohon ampun kepada Tuhan dan senantiasa meminta ridhoNya untuk setiap hal yang dikerjakannya. Ketidakberdayaannya ini tidak berarti membuat ia kuat untuk tinggal di neraka, tetapi rasanya tidak pantas juga jika ia menjadi salah satu penghuni surga bersanding dengan Nabi Muhammad saw. Pada akhirnya yang dapat manusia lakukan hanyalah menjadi manusia yang sebenar-benarnya manusia dengan penuh ketaatan menyembah Allah SWT, berharap bahwa ia selalu dipilihkan jalan hidup yang lurus seperti yang tergambar dalam lagu "Duh Gusti".

\section{Ingsun Amemuji}

Ingsun amemuji asmaning Alloh,

katelase dunya sirik akherat, sembah bekti kula nyuwun paring ridho,

kathahe dosa nyuwun pangapura.

Illahilastullifirdausiaahla, walaal aqwa 'ala naril jahiimi, fahablitaubatan waghfirdzunubi, 
fainnakaghofirudz dzanbil'adziimi. Ilaahi'abduka 'asin 'abdaka, mufirrodzin dzunuub waqod 'adzaka. $2 x$

Duh Gusti kawula sanes ahli suwarga, ananging kawula boten kiyat teng neraka. Mugi ingsun muji asma Kanjeng Nabi, Muhammad wiwiting cahya kang dumadi, ibarating manungsa sujud marang Gusti, kula jroning umat ingkang sejati. Wa hubli'akisun fikulli mi yaumi, wa dzambi syahidun kaifakhtimaali.

\section{Duh Gusti}

Duh Gusti... mugi paringa ing margi

kaleresan,

kados margine manungsa kang panggih

kanikmatan,

sanes margine manungsa kang Paduka laknati.

\section{Ajaran Kebaikan}

Emha Ainun Nadjib tidak pernah meninggalkan esensi dakwah pada umumnya yakni senantiasa mengajak seluruh umat manusia untuk senantiasa berlomba-lomba dalam kebaikan dan taqwa. Walaupun beliau seorang kritikus yang begitu tajam pemikirannya, tetapi riwayat kehidupannya yang pernah mengaji di Pondok Pesantren membuat kehidupannya tetap dilandasi dengan religiusitas yang tinggi kepada Tuhan. Ajaran-ajaran kebaikan yang ingin beliau sampaikan juga sering dituliskan dalam bentuk lagu-lagu agar lebih mudah diterima di kalangan masyarakat pada umumnya. Salah satu lagu ciptaannya yang mengandung ajaran kebaikan adalah lagu "Ning Dunya Pira Suwene".

\section{Ning Dunya Pira Suwene}

Ning ndunya pira suwene, njur bali ning panggonane, ning akerat ya sejatine, mung amal becik ya sangune, nanging aja ngucap 'bodho ya ben', golek ilmu kudu telaten.

\section{Suluk Pertobatan}

Kawruhana dununge wong urip puniki, Lamun mbenjang yen wus palastra, Wong mati nyangndi parane,
Umpamakna peksi mabur,

Kesah saking kurungan neki,

Umpamakna wong lunga sonja,

Njang sinanjang,

Wong lunga wajibe mulih,

Mulih neng ngisor semboja.

Kedua lagu di atas mengajak manusia agar ingat asal usul kehidupan, bahwa hidup itu hanyalah sementara dan kematian itu pasti. Manusia itu tidak boleh terlena dalam kemewahan hidup di dunia ini, karena pada hakikatnya manusia hidup di dunia ini hanya sementara saja, ibarat orang yang sedang berlabuh hanya mampir sebentar saja. Dalam ungkapan Jawa ada pepatah urip kuwi mung mampir ngombe. Mungkin lagu tersebut tercipta dari telaah pepatah tersebut. Yang namanya orang hanya berlabuh itu berarti ia hanya tinggal sementara saja, tidak akan lama dan pasti suatu saat harus kembali ke tempat asalnya. Seperti itulah kehidupan. Bahwa hidup di dunia ini hanya sementara sedangkan kehidupan di akhirat nantilah yang abadi. Oleh karena itu, jangan sia-siakan hidup dengan berbuat semaunya sendiri. Bagi generasi muda ajakannya bahwa rajin-rajinlah menuntut ilmu, jangan pernah mudah menyerah dalam mencarinya karena kebodohan akan menjerumuskan kita dalam kesengsaraan hidup.

Dalam rangkaian lirik lagu Syiir Waton diharapkan manusia agar tidak lelah mengaji agar mengerti ajaran Islam lebih dalam lagi beserta hukum-hukum Islam yang ada. Ketika kita mau mengaji, maka ilmu yang kita dapatkan bisa menjadi sangu untuk meraih hidup yang lebih mulia. Untuk meraih hidup yang mulia itu tentu tidak gampang karena kita manusia dituntut untuk melakukan banyak hal dari mulai laku tarekat, hakikat sampai akhirnya nanti bisa mencapai makrifat. Ketiga laku ini adalah tingkatan keimanan manusia kepada Allah SWT yang tercantum dalam Al Qur'an sebagai sebuah ajaran suci. Barangsiapa ingin meraih kesempurnaan hidup maka harus mencapai tingkatan makrifat. Manusia juga dituntut untuk hidup sabar, mau menerima semua hal yang terjadi pada hidupnya karena semua itu sudah ditakdirkan oleh Allah SWT. Sesama manusia juga harus hidup rukun, jangan saling 
bermusuhan atau melakukan perbuatan yang menyakiti orang lain. Hal ini harus dijalani oleh setiap manusia jika ingin dinaikkan derajat keimanannya oleh Allah SWT. Walaupun perbuatan yang baik seperti ini akan tidak disukai oleh orang lain, tetapi jangan risau karena yang menilai baik buruknya setiap perilaku kita hanya Allah. Janganlah takut untuk bertaubat karena Allah maha mengampuni setiap dosa kita. Ketika kita mau melakukan setiap hal didasari rasa keimanan kita kepada Allah maka janji Allah adalah surga bagi kita.

\section{Idiom-idiom Jawa}

Sebagai seorang budayawan, Emha Ainun Nadjib juga giat membuka kesadaran masyarakat untuk mencintai budayanya sendiri. Hal ini dapat terlihat dari pemakaian idiom-idiom Jawa dalam dakwahnya. Penelaahan suatu masalah seringkali juga dikaitkan dengan budaya Jawa seperti yang tercantum dalam petikan dakwahnya berikut ini.

"kita lak punya unen-unen, tata tentrem kerta raharja, gemah ripah loh jinawi. Kalau di Al Qur'an semua kalimat tadi direngkes jadi Baldatun toyyibatun, ga ada wa Robbun ghofur. Kalau dalam Islam Baldatun toyyibatun itu selalu berdampingan dengan wa robbu ghofur. Nah, wa robbun ghofur inilah yang seharusnya jadi prinsip nasional bangsa Indonesia. Allah itu sudah siap akan mengampuni karena Allah tahu kalau kita pasti akan salah dikit-dikit, maka Allah siap dengan semua ampunan-ampunannya. Maka itu menjadi baldatun toyyibatun wa robbun ghofur."

Ungkapan tata tentrem kerta raharja, gepah ripah loh jinawi sering dipakai Cak Nun untuk menggambarkan tujuan manusia dalam kehidupannya. Setiap orang tentu ingin mencapai kemakmuran dan kedamaian dalam kehidupannya. Tujuan hidup manusia ini sebenarnya selaras dengan apa yang telah disampaikan Allah SWT dalam firmannya di Al Qur'an yakni baldatun toyyibatun wa Robbun Ghofur. Arti ungkapan tata tentrem kerta raharja, gepah ripah loh jinawi ditelaah baru sekedar baldatun toyyibatun sehingga masih kurang wa Robbun Ghofur nya. Padahal ampunan dari Allah itu sangatlah penting ketika kita melakukan suatu perbuatan. Hal ini dikarenakan kita tidak tahu secara pasti apakah setiap tindakan yang kita lakukan itu benar atau salah. Maka, wa Robbun Ghofur ini sangatlah penting ditambahkan dalam ungkapan tata tentrem kerta raharja, gepah ripah loh jinawi agar setiap ketentraman, kebeningan jiwa, utamanya perilaku termasuk pekerjaan yang kita raih dalam hidup ini senantiasa termaafkan oleh Allah SWT.

Pengibaratan-pengibaratan setiap perilaku kita dalam hidup ini dengan hal-hal yang berbau kejawaan juga tergambar dalam petikan dakwahnya berikut ini.

"nak cangkul ki fungsi apa? Fungsi ekonomi. Bahkan mentri ekonomi pun ketika ditanya oleh temennya bilang "Sik aku lagi macul", maksude lagi mencari nafkah. Kalau pedang fungsi apa? Fungsi politik dan kekuasaan. Sekarang kalau keris, keris ki fungsi apa? Ada yg bilang ideologi, kewibawaan. Keris ki fungsinya atau nilainya yaitu ritual. Saiki nak AdiTV, TransTV, RCTI, dll kae fungsine $k i$ pacul, pedang, po keris? Disamping pacul pas ana pilpres dadi pedang. Saiki kerise pas kapan? Dadi AdiTV kuwi kudu duwe pacul, punya pedang, terus duwe tujuan sebagai pusakanya wong Yogyakarta. Dadi itu semua hanya sebatas terminologi saja.

Dari gambaran petikan dakwah Cak Nun di atas pada hakikatnya beliau ingin menggambarkan tentang fungsi keris sebagai sebuah pusaka. Pemilihan keris sebagai perlambang sebuah pusaka ini disebabkan lantaran keris merupakan salah satu peninggalan budaya Jawa yang bernilai agung. Keris memiliki makna filosofis yang dalam jika ingin mengkajinya lebih dalam. Sebenarnya, keris ini melambangkan sesuatu yang baik karena memiliki aji atau pamor kebaikan, tetapi banyak persepsi yang salah mengenai keris ini. Penggunaan keris yang keliru yaitu identik dengan pembunuhan atau kekerasan lalu bernuansa mistis di masa lalu menjadikan keris ini semakin menghilang 
keberadaannya. Cak Nun mencoba membuka kembali pemikiran orang-orang tentang kebermanfaatan keris dalam kehidupan ini, salah satunya dengan membandingkan antara pemakaian pacul (cangkul), pedang, dan keris. Pacul merupakan terminologi alat yang identik dengan alat ekonomi, pedang identik dengan kekuasaan, dan keris identik dengan pusaka. Keberhargaan sebuah pusaka haruslah dijaga karena ketika pusaka itu dijaga maka baik itu jalan kekuasaan maupun ekonomi akan mengikuti dengan sendirinya. Jadi, ketika kita memandang sesuatu yang berbau budaya jangan langsung menganggap sesuatu itu salah, tetapi berfikirlah dari sisi lain yang lebih positif karena setiap kebudayaan adalah kekayaan yang harus terus dilestarikan.

\section{Permasalahan Ormas Islam}

Pemikiran Emha Ainun Nadjib yang plural membuatnya mampu diterima di berbagai macam ormas Islam, termasuk NU dan Muhammadiyah. Cara dakwah beliau yang empan papan dapat diterima dengan senang hati dengan anggota kedua ormas Islam terbesar di Indonesia tersebut. Mungkin kalau saja beliau itu termasuk Kiai NU maka beliau pasti tidak bisa diterima oleh warga Muhammadiyah, begitu sebaliknya. Akan tetapi, pemahaman beliau mengenai ciri khas masing-masing ormas Islam itu membuatnya mampu beradaptasi dengan para tokoh besar pimpinan ormas $\mathrm{Mu}-$ hammadiyah maupun NU. Hal ini mungkin pula dilatarbelakangi dengan riwayat pendidikan beliau yang pernah belajar di pendidikan Muhammadiyah maupun lembaga pendidikan NU. Hal ini tampak seperti petikan isi dakwah beliau berikut ini.

"supaya saya tidak mengkultuskan Muhammadiyah merga ana ulama $N U$, mulane tak celukke ki yo kaya penggedene muhammadiyah. Nanti kalau anda berurusan dengan kitab kuning ke Pak Muzammil, kalau ada urusan sama kitab ijo itu ke Pak Mushowir. Alhamdulillah dari beberapa paguyuban yang saya dirikan, yang paling aktif ya yang ada Pak Mushowir ini namanya NahdatulMuhammadiyah. Tugasnya apa?
Ya mengurusi konflik-konflik antara keduanya. Yen ana masyarakat sing padu ditemokke, diandharke dalildalilnya, dikuati nas-nasnya ben mereka paham satu sama lain."

Pengetahuan mengenai ormas Islam yang diketahui Cak Nun tidak hanya sebatas Muhammadiyah dan NU saja. Aliran-aliran lain seperti Sunni dan Syi'ah yang sedang berseteru juga dipahami secara mantap oleh beliau. Aliran Wahabi, Sunni, Ahlu Sunnah wal Jama'ah, Ahmadiyah, LDII, Hizbut Tahrir merupakan jenis aliran Islam lainnya yang terdapat di Indonesia. Ciri khas masing-masing ormas Islam tersebut sangat dimengerti oleh beliau, maka dalam dakwahnya kadang-kadang beliau sering memberikan sindiran menggunakan ciri masing-masing ormas tersebut. Pada dasarnya Cak Nun bukanlah orang yang menganut aliran tertentu, beliau tidak ingin terikat dengan satu ormas karena menurutnya cara berIslam yang benar adalah sesuai dengan ajaran Islam yang dibawa oleh Rasulullah SAW tidak berdasarkan ajaran suatu ormas. Berikut ini merupakan petikan dakwah Cak Nun yang menggambarkan pengetahuannya tentang ormas-ormas Islam yang ada.

Hasil daripada analisis teks yang dilakukan bertumpu pada upaya untuk mengungkapkan kekuatan ungkapan dalam pesan dakwah dan lirik lagu-lagu Emha Ainun Nadjib yang dinyanyikan bersama grup musik Kiai Kanjeng. Lirik-lirik lagu beserta isi dakwah Emha Ainun Nadjib berhasil memperlihatkan kekuatan produktif musik dalam dakwah dan kapasitasnya sebagai sebuah bentuk budaya dan medium ekspresi untuk mengajak atau membangkitkan dukungan pada suatu gerakan atau kasus tertentu. Selain itu isi lirik-lirik lagu beserta dakwah beliau juga dapat membangun solidaritas dan kohesi sosial di kalangan lapis masyarakat yang menjadi penikmatnya, mempromosikan kesadaran dan membangkitkan solusi terhadap problema sosial, atau secara sederhana sekedar memberi harapan bagi sebagian besar khalayak yang masih terus menjadi pendengar setianya. Di sini musik sebagai bagian dari proses membentuk dan menggunakan budaya populer, seringkali mengungkap- 
kan ketegangan dan konflik terhadap hal-hal yang diinginkan dan ditransformasikan. Proses ini mencakup hubungan-hubungan yang pada permukaan terlihat murni personal, tetapi sesungguhnya merefleksikan adanya transformasi sosial yang lebih dalam dan konflik mengenai konsepsi masyarakat yang lebih luas.

Pada analisis di atas dapat terlihat bagaimana pesan dakwah dan teks-teks musik yang disajikan oleh Emha Ainun Nadjib beserta grup musik Kiai Kanjeng dalam aspek-aspek tertentu telah berperan sebagai medium yang potensial untuk mengkonstruksi makna melawan hegemoni nilai-nilai dominan kekuasaan yang isinya dengan jelas menyuarakan persoalan politik, sosial, moral, dan lingkungannya. Selain itu masalah ketauhidan, ajaran-ajaran kebaikan, dan penyentuhan unsur budaya Jawa juga menjadi bagian dari pembahasan dakwah Cak Nun yang juga dituliskan dalam lagu-lagu karangannya. Kekritisan lagu-lagu karangan beliau dalam melantunkan suara-suara ketidakadilan tergambar secara jelas dan dapat dinikmati sebagai sebuah sindiran terhdap para penguasa negeri yang telah bertindak sewenang-wenang dengan jabatannya. Lagu-lagu dakwah Emha Ainun Nadjib ini tidak hanya lahir untuk memaparkan kritik sosial yang mendalam, tetapi baik lagu maupun isi dakwahnya juga membentangkan segala problema yang terjadi pada bangsa Indonesia ini.

Sebagaimana kita tahu, persoalan resistensi begitu mendasar dalam kajian budaya dan media yang sedang berkembang hingga saat ini. Isu resistensi sebagaimana yang telah dijelaskan sebelumnya merupakan perhatian yang paling fundamental dalaJohn Fiske telah mengidentifikasi dua corak utama resistensi: Pertama, resistensi sebagai kekuatan untuk mengkonstruksi makna, kesenangan, dan identitas sosial (Fiske menyebutnya sebagai kekua$\tan$ semiotis); dan kedua, resistensi sebagai kekuatan untuk mengkonstruksi sistem sosioekonomi (Fiske menyebutnya kekuatan sosial) (Fiske, 1987:316). m semua bentuk ekspresi musikal yang dibahas dalam penelitian ini.

\section{SIMPULAN}

Dari hasil penelitian yang telah dilakukan dapat dihasilkan beberapa kesimpulan yang dilihat dari analisis data yang dilakukan. Pertama, penelitian ini menunjukkan bahwa lagulagu yang dibawakan oleh Emha Ainun Nadjib bersama Kiai Kanjeng dihasilkan dengan suara rakyat yang selama ini telah dibisukan. Ideologi perlawanan terlihat menonjol dalam isi dakwah maupun teks-teks lagu yang dikarang oleh Emha Ainun Nadjib. Isi dakwahnya membicarakan wujud ketimpangan dan berusaha membongkar segala ketidakadilan yang telah terjadi lewat lagu-lagu dan dakwahnya. Tidak cukup dengan lontaran dan kritikan terhadap sistem undang-undang yang zalim malahan terhadap sosok dan sifat bagi seorang wakil rakyat di negeri ini. Penekanan isi dakwah dan lagu-lagunya juga bersifat untuk membangkitkan kesedaran dan suara rakyat yang sering termajinal terhadap kekuasaan.

Kedua, penelitian ini juga menunjukkan bahwa keberadaan lagu-lagu yang dibawakan Emha Ainun Nadjib juga membuktikan bahwa aktor masyarakat sipil juga bisa memanfaatkan potensi musik dan dakwah sebagai medium resistensi. Dari hasil analisia teks-teks lagu yang dibawakan Kiai Kanjeng dan isi dakwah Emha Ainun Nadjib dalam acara Mocopat Syafaat telah membentuk budaya resistensi dalam musik dan dakwahnya. Tema-tema yang bernada protes terhadap kekuasaan yaitu satire terhadap kekuasaan, penghormatan terhadap sejarah masa lampau, ekspresi solidaritas kelas bawah melalui tema-tema ketauhidan dan ajaran kebajikan, serta komentar sosial kritis disuarakan dengan dibingkai idiologi-idiologi yang berbau kebudayaan Jawa. sebagai salah satu elemen budaya, musik dapat dikatakan sebagai suara dari yang tak tersuarakan, seperti sebagai penunjukan identitas diri, sebagai perlawanan atau protes, sebagai suara kebebasan, juga terdapat nilai kejujuran dan spontanitas dimana musik juga dapat diintegrasikan kedalam bingkai dakwah Islami.

\section{DAFTAR PUSTAKA}

Adorno, T. (1976). Introduction to the Sociology of Music. New York: Seabury Press

Anshari, E. S. (1986). Wawasan Islam: PokokPokok Fikiran Tentang Islam. Bandung: CV. Diponegoro. 
Balliger, Robin. (1999). "Politics". In Bruce Horner and Thomas Swiss (eds), Key Terms in Popular Music and Culture, pp. 57-70. Oxford: Blackwell.

Cheney, G., \& Cloud,D. L. (2006). Doing Democray, Engaging The Material:E mployeeParticipationandLabor Activity in An Age of Market Globalization. Dalam Management Communication Quarterly, 19. 501-540.

Depdiknas. (2002). Kamus Besar Bahasa Indonesia. Jakarta: Balai Pustaka.

Fairclough, N. (2013). Critical Discourse Analysis : The Critical Study of Language. New York: Routledge.

Fiske, J. (2007). Cultural and Communication Studies - Sebuah Pengantar Paling Komprehensif. Yogyakarta: Jalasutra.

Gazalba, S. (1989). Mesjid Pusat Ibadat dan Kebudayaan Islam. Jakarta: Pustaka al-husna.

Hollander, J. A. dan Einwohner, R.L. (2004). Conceptualizing Resistance. Didalam Sociological Forum 19 (4): 533-53.

Jorgensen, Marianne \& Louise J. Philips. (2007). Analisa Wacana, Teori, dan Metode. Yogyakarta: Pustaka Pelajar.
Kotarba, J. A. dan Vannini, P. (2009). Understanding Society through Popular Music. London: Routledge.

Lahpan, N. Y.K. (2002). Resistensi Pribumi Terhadap Kolonialisme dalam Siti Rayati Karya Moh. Sanoesi. Tesis pada Jurusan Ilmu Sastra Fakultas Ilmu Budaya Universitas Gajah Mada Yogyakarta.

Littlejohn, S. W. (2002). Theories of Human Communication 7th Ed. USA: Wadsworth Group.

Poerwadarminta, W.J.S. (1976). Kamus Besar Bahasa Indonesia. Jakarta: Balai Pustaka.

Saputra, W. (2012). Pengantar Ilmu Dakwah. Jakarta: PT Raja Grafindo Persada.

Storey, J. (1996). Cultural Studies and the Study of Popular Culture: Theories and Methods. Athens: Edinburg Press and University of Gergio Press.

Syukir, S. (1983). Dasar-dasar Strategi Dakwah Islam. Surabaya: Al-Ikhlas.

Titscher, S. .et.al (Ed). (2009). Metode Analisis Teks dan Wacana. Yogyakarta: Pustaka Pelajar.

Zuhdi, M. H. (2012).Dakwah dan Dialektika Akulturasi Budaya. Jurnal Religia Vol. 15 No. 1. 